\title{
Notas a propósito de los géneros de opinión, información y ficción en los medios colombianos
}

\section{Por Fabio López de la Roche}

Este ensayo intenta plantear una serie de situaciones relacionadas con el funcionamiento global y nacional de la información noticiosa y del género de opinión, pero también de los géneros de ficción y de las ofertas de las industrias culturales productoras de bienes simbólicos, desde el punto de vista de la representación de la política y de lo político, pero también de la representación socio-cultural de la sociedad. Integramos en este escrito estas dos esferas de la comunicación masiva contemporánea, que muchas veces no se interrelacionan ni se mezclan en los análisis debido a las especializaciones disciplinarias de quienes escriben separadamente sobre estos temas aparentemente inconexos. Sin embargo, una mirada integral del sistema comunicativo y del funcionamiento del poder mediático y comunicativo contemporáneo en nuestras sociedades, debe prestar atención a las interrelaciones entre las esferas políticas y culturales de la comunicación masiva. La ciudadanía, la participación, el reconocimiento y la representación de la diversidad cultural se juegan tanto en las unas como en las otras.

En el abordaje de los géneros de información y opinión se trabajará ampliamente el tema del cubrimiento por los medios informativos colombianos del conflicto armado y el proceso de paz con las FARC durante la administración Pastrana. En este punto serán abordados algunos de los problemas y dificultades para construir una información equilibrada y objetiva en medio de contextos político-culturales de intolerancia ideológica y de polarización política.[1]

¿Hacia un nuevo ciclo de imperialismo y antimperialismo por obra de George Bush y del orden global contemporáneo?

Cuando algunos creíamos -tal vez ingenuamente- en que el imperialismo era un asunto del pasado, una fase histórica del capitalismo lejana en el tiempo y ya superada, la actual política de la administración norteamericana de George Bush, con su caza de brujas internacional y con sus imposiciones a nivel de la diplomacia bilateral, está contribuyendo a un revival antimperialista y antinorteamericano. La exigencia a Colombia de aceptar la inmunidad jurídica de los soldados norteamericanos actuantes en Colombia frente a la Corte Penal Internacional en caso de verse involucrados en violaciones a los derechos humanos y en crímenes de lesa humanidad, no puede merecer otro calificativo que el de imperialista.

Pero los imperios pueden ejercer como tales de manera más fácil y sin mayores oposiciones, cuando lo hacen ante naciones fragmentadas, con clases dirigentes ilegítimas o con una legitimidad muy fragmentaria, sin autoridad ante sus pueblos $y$ ante la sociedad internacional, y ante estados económicamente -y ahora en nuestro caso- militarmente dependientes. Cuando un gobierno como el de Pastrana le toca ir a poner la totuma en actitud mendicante ante el Congreso y el Ejecutivo norteamericanos, porque el conflicto interno se le salió de madre -a él y a los gobiernos anteriores-, porque los recursos del presupuesto interno no le alcanzan para cubrir los gastos necesarios para hacer frente a los enemigos político-militares internos, no puede tener dignidad ni tener una voz propia y fuerte en temas en los cuales debería tenerla, como el del narcotráfico, la sustitución de narcocultivos, las alternativas al prohibicionismo y a la erradicación de los cultivos de coca a través de la fumigación.

Estos tiempos imperiales tienen su correlato comunicativo en la hegemonía de ciertos circuitos informativos como CNN y otros espacios mediáticos dominantes en medio de la globalización comunicativa actualmente hegemónica. Ante estos formatos y circuitos hegemónicos, frente a sus sesgos, silencios, prioridades mercantiles traducidas en verdades a medias, necesitamos no sólo desarrollar una actitud crítica y deconstructiva desde las 
audiencias, los espacios educativos y de crítica cultural, sino adicionalmente y en un sentido alternativo y política y culturalmente radicalmente pluralista, avanzar en la capacidad de tejer redes de información que permitan aproximarnos de manera más fidedigna y menos manipulada a las realidades nacionales e internacionales de nuestros días. Muy difícilmente en este momento, para colocar un ejemplo, podemos informarnos a nivel de América Latina, desde aproximaciones equilibradas, plurales y complejas -no simplistas y unidimensionales como suelen ser hoy día la opinión y la información en nuestro país- sobre las realidades del chavismo en Venezuela, el fenómeno Lula da Silva en la coyuntura electoral brasileña, el caso de Evo Morales en la política boliviana, o a la situación política interna colombiana, indigerible e inentendible para una amplísima audiencia en América Latina que ve por la televisión algunos síntomas de nuestra tragedia pero difícilmente puede comprender sobre la base de esa información la complejidad de situaciones y sucesos políticos y militares que ocurren diariamente en Colombia. Creo que requerimos actualmente de un diálogo latinoamericano más complejo, más plural, polifónico y argumentado, con puntos de vista y opiniones antinómicas, con matices y posiciones intermedias, que antes que instancias de inculcamiento de determinadas posiciones y actitudes políticas, sirvan de foro para inteligir nuestros problemas y para discernir entre diversas opciones y alternativas de desarrollo. $Y$ además del diálogo latinoamericano, de un diálogo Sur-Sur que permita dialogar entre exclusiones, pobrezas y conflictividades sociales y políticas compartidas, pero también entre experiencias de búsqueda de relaciones económicas y sociales nacionales y globales más equitativas, movimientos sociales y culturales, recreaciones estéticas y artísticas de la memoria, procesos de reconciliación nacional o de construcción de cultura ciudadana.

\section{La concentración económica y el empobrecimiento del debate ciudadano}

La concentración de los medios de comunicación en manos de los grandes grupos económicos y financieros, la pérdida de audiencia de los canales televisivos 1 y A ante el auge de los canales privados RCN y Caracol y la falta de una política pública coherente para su rescate y desarrollo, la desaparición del diario El Espectador como diario nacional y su adquisición por el grupo Santodomingo, la nueva situación hegemónica del periódico El Tiempo casi como único espacio del periodismo de prensa escrita a nivel nacional, constituyen factores internos que están incidiendo en la homogeneización de la opinión y en la pérdida de pluralidad de voces e interpretaciones en el sistema informativo y comunicativo colombiano, sin que queramos decir con esto que la situación anterior en cuanto a diversidad política y cultural en nuestro sistema de medios fuera la mejor. Si antes los noticieros televisivos estaban concentrados en manos de las familias o empresas mediáticas de cinco expresidentes de la república, hoy día están en manos de los grandes potentados económicos.

La situación de abandono de los canales procedentes del sistema mixto, llevó a la desaparición de varias programadoras históricas que habían logrado un lugar importante en la producción televisiva nacional así como en la recordación de la teleaudiencia. 0 a su reacomodo funcional a las demandas del mercado global (léase norteamericano) y de los gustos comercialmente moldeados de las audiencias hispanas en Estados Unidos. No hubo una planeación responsable desde el punto de vista político y cultural, de la reconversión del sistema mixto a un sistema multicanales de base privada, que preservara las cosas buenas del anterior ordenamiento televisivo y la trayectoria de algunas programadoras que hicieron época en el desarrollo de géneros y estilos en la televisión colombiana.[2]

La metáfora de ese abandono de los canales 1 y $\mathrm{A}$ ha sido en los últimos años la presencia reiterativa y rutinaria en la emisión de esos dos canales, de las televentas y de la oferta de fajas y demás dispositivos para adelgazar, evidencia simultánea del peso creciente de ciertas tendencias livianas y consumistas del mercado global, pero también de la desidia de nuestra clase dirigente, de su escasa o nula preocupación por la diversidad y el pluralismo político y cultural de la comunicación masiva, y de su complicidad con los grandes grupos de poder económico y financiero.

Mientras tanto, algunos noticieros y espacios de opinión de estos dos canales han tenido que desaparecer, reducir sus plantas de personal, en algunos casos compartir entre dos noticieros sus camarógrafos y periodistas para poder mantenerse con menores costos, o finalmente 
fusionarse en un solo telediario. $Y$ los periodistas han terminado a menudo desempleados, haciendo dos trabajos por el precio de uno, o trabajando a destajo en múltiples cubrimientos y labores free lance que reducen notoriamente la calidad de la investigación y la escritura periodística.

Algunos de los resultados de esta apertura y reconversión mercantilista son hoy día los abusos de la pauta publicitaria expresados en la publicidad camuflada o abierta en noticieros, ficción y cine de autor; el destierro de los programas de opinión de los horarios Triple A en virtud de la telenovelización de los horarios de alta sintonía; la conversión consecuente de los programas de debate y de opinión en espacios para noctámbulos; y un exagerado unanimismo ante temas que demandarían para su esclarecimiento amplios, fuertes y plurales debates ciudadanos.

Logros y miserias del cubrimiento periodístico del proceso de paz en medio del conflicto armado: lo importante contra lo rentable

El desarrollo del proceso de paz durante la administración Pastrana, al no pactarse un cese al fuego, tuvo lugar en medio del conflicto armado. De esa manera los hechos noticiosos derivados del conflicto bélico (tomas de pueblos, estallidos de cilindros-bombas, masacres y enfrentamientos militares), altamente noticiables en virtud de su carácter espectacular y dramático, terminaron a menudo haciendo mucho ruido y opacando la visibilidad de algunos avances y logros en la mesa de negociación, muchos de ellos poco espectaculares, y visibles sobre todo para el analista juicioso y agudo, el negociador o el experto en resolución de conflictos.

Hay que reconocer en este punto los importantes esfuerzos e iniciativas adelantados desde la prensa escrita, particularmente desde las Unidades de Paz como también desde otras secciones, para complejizar y dar fondo histórico a la lectura ciudadana del conflicto, para ofrecerle a los lectores elementos de juicio acerca de cómo han sido los procesos de negociación de conflictos armados internos en otras latitudes y cómo se propiciaron o se dificultaron los procesos de aproximación entre las partes. No sólo entrevistaron a personajes como el señor Villavicencio, negociador en Suráfrica, a comandantes centroamericanos como Ana Guadalupe Martínez, a mediadores europeos y norteamericanos en otros conflictos bélicos, sino que construyendo una relación dialógica con saberes sobre el conflicto armado colombiano menos coyunturales y más históricos y estructurales, acumulados producto de la reflexión académica de universidades e institutos de investigación nacionales, intentaron darle fondo y perspectivas complejas de análisis al ciudadano lector de prensa.

Sin embargo, y en notorio contraste con lo que pasaba en prensa escrita con las Unidades de $\mathrm{Paz}$, los dueños y directores de noticieros televisivos, escenario mediático hegemónico en la construcción de la visibilidad comunicativa masiva del proceso de paz, no evidenciaron una particular conciencia de las funciones, roles y responsabilidades en la configuración de los climas de opinión pública hacia el proceso de negociación.

En esos espacios claves para la orientación de un proceso de reconciliación nacional, siguieron predominando el rating y el interés comercial sobre el interés nacional y el interés público. En el cubrimiento de los sucesos informativos de la vida nacional desde los telediarios, primó durante el proceso de paz con las FARC y continúa primando ahora después de la ruptura del mismo, un periodismo de relación de hechos de orden público, presentados de manera inconexa y fragmentaria, privilegiando las escenas y situaciones dramáticas y las expresiones de dolor de las víctimas, que abundan en nuestro país y que constituyen hechos altamente "noticiables" desde las lógicas y rutinas ocupacionales de la profesión periodística. No hay información sobre las estrategias militares y políticas de los actores de la guerra, sobre sus proyecciones estratégicas en territorios y geografías regionales, sobre los aspectos tecnológicos y propiamente militares del conflicto armado interno, y menos sobre la economía política de la guerra y las maneras como ella explicaría el comportamiento de los actores armados. 
En este periodismo televisivo de relación de hechos de orden público inconexos y caóticos ni siquiera se utilizan mapas del país y de sus regiones para ayudarle a los colombianos a comprender el curso diario de los hechos bélicos. Las víctimas de las masacres paramilitares o guerrilleras aparecen muchas veces sin identidades claras, sin nombres ni oficios, como meros datos estadísticos, y las notas periodísticas que cubren estos hechos de terror con frecuencia penetran poco en los móviles de los hechos y en su ubicación dentro de las estrategias políticas y militares de quienes los cometen.

Causa y consecuencia de este periodismo coyunturalista, dramático y sensacionalista, es la ausencia en los espacios noticiosos televisivos de una agenda temática propia con una jerarquía de temas y asuntos para el debate ciudadano, formulada desde sus equipos de trabajo y sobre todo desde sus directores y jefes de redacción. En ellos ha desaparecido la editorialización, que años atrás estuvo presente en los telediarios, están ausentes el análisis y la contextualización histórica de la noticia, e incluso géneros como la crónica y el reportaje tienen hoy día muy poca presencia.

A este primer componente de nuestros noticieros, el de las noticias de orden público, se suman un segundo y un tercero: el sobredimensionamiento de la información deportiva en la estructura general del telediario, y la presencia igualmente desmedida de las notas de farándula, la vida privada de los famosos, las nalgas (femeninas, nunca masculinas, tal vez para no subvertir viejos órdenes patriarcales y machistas), y por supuesto el infaltable mundo del fashion. Sin tener nada contra estos campos de la vida social contemporánea, - estoy lejos de pensar que todo en ella tenga que ser reflexivo, profundo o heavy, creo que esos temas y asuntos deben tener su lugar propio en la programación televisiva, a través de géneros y programas especializados en deporte, farándula o en fashion, y los noticieros conservar una cierta jerarquía temática alrededor de la construcción de la agenda mediática para la deliberación ciudadana de los más importantes asuntos públicos en horizontes temporales inmediatos, mediatos o de largo alcance.

Los difíciles equilibrios políticos e ideológicos, las tomas de partido de los periodistas, la pasionalidad de las fuentes y la transmisión no controlada de sus intolerancias discursivas

La cultura política de una sociedad nacional, así como las culturas políticas particulares de actores políticos y sociales de ella tales como sus políticos profesionales, su estamento militar, su sindicalismo, su empresariado, su izquierda, sus trayectorias históricas y sus particulares procesos de construcción de sentidos y representaciones sobre la nación y sobre el otro-político, están a la base de los procesos de comunicación política en una sociedad. Constituyen la trama de significaciones y sentidos desde los cuales se realizan la producción y la recepción de los mensajes de los medios de comunicación.

En una sociedad como la colombiana, profundamente fragmentada desde el punto de vista de sus exclusiones sociales, notoriamente polarizada, con sectores amplios de su población que han recibido agravios y acumulado resentimientos y odios derivados del boleteo, el secuestro o el homicidio guerrillero, de la masacre paramilitar, del despojo de sus bienes y el desplazamiento forzado debido a la guerrilla o al paramilitarismo, o de abusos y extralimitaciones de miembros de organismos militares, policiales y de inteligencia del Estado, es muy difícil, -podríamos decir casi imposible- un funcionamiento equilibrado y ecuánime del periodismo y de los medios de comunicación masiva a la hora de cubrir un proceso de paz en medio de un conflicto armado. Esos odios y polarizaciones no pueden no afectar los procesos de producción y de recepción social de la información noticiosa sobre el conflicto armado y sobre la negociación.

El cubrimiento del proceso de paz se vio muy afectado por esas visiones pasionales del conflicto colombiano que aparecen a menudo hoy día, atropelladoras y viscerales, en cualquier conversación cotidiana sobre el tema entre desconocidos, en eventos académicos, en conversaciones de café o debates en recintos universitarios. En una situación de tan fuerte polarización de la opinión ante el conflicto armado interno es por ello mismo mucho más grave la ausencia desde los espacios masivos televisivos de opinión e información, de 
arreglos institucionales conducentes a un cubrimiento más cuidadoso y equilibrado de la información sobre el conflicto armado, el proceso de paz y la negociación política.

Lo que observamos a menudo sobre todo en los noticieros televisivos, fue la toma de partido a favor del Estado, de las visiones de los empresarios dueños de los medios, y la toma de partido por las opiniones de las fuentes oficiales consultadas, reproducidas muchas veces como si fueran la palabra de Dios.

Con respecto a la política gubernamental de paz, no hubo nunca un seguimiento crítico y una clara fiscalización por parte de los medios y del periodismo, a las acciones y omisiones de quienes la manejaron. Un seguimiento crítico e independiente por parte del periodismo a la conducción gubernamental del proceso de paz tampoco tenía que reducirse, como muchas veces lo hizo, a darle la voz a los críticos de derecha y a los enemigos acérrimos y declarados de la negociación política en los partidos o en el congreso.

Sin sugerir que estas voces debieron ser ignoradas, hay que anotar que con respecto al proceso de paz, la crítica generalmente recayó sobre la falta de voluntad política de la insurgencia para sentarse seriamente a negociar en la mesa (crítica por lo demás válida), pero muy poco se abordaron las insuficiencias y falta de compromiso del gobierno con un proyecto serio y coherente de paz y de país posconflicto, más allá de la retórica y la indudable buena voluntad del presidente Pastrana hacia la paz.

No hubo una crítica a fondo sobre una serie de aspectos que evidenciaban la ausencia de un proyecto gubernamental conducente a una senda clara de reconciliación nacional: la ausencia de un proyecto social reformista que ataque las condiciones estructurales que alimentan la insurgencia sobre todo en áreas campesinas deprimidas y zonas de colonización; la falta de garantías para la actividad sindical, periodística, judicial, para la política de oposición o de defensa de los derechos humanos, en un país con el más alto índice de asesinatos de líderes sindicales y periodistas en el mundo (¿quién se va a embarcar seriamente en un proceso de paz sin garantías para la vida y la seguridad personal y familiar?); el no diseño de una política civil y militar de protección a la población civil en medio del conflicto; la carencia de liderazgo con respecto a una reforma política de fondo; la falta de una política eficaz y de participación ciudadana contra la corrupción oficial y los delitos de cuello blanco; la fragmentaria representatividad social de los negociadores gubernamentales; la ausencia de una política de empleo; las tensiones permanentes entre el ejecutivo y el estamento militar alrededor de la política de negociación y de la zona de despeje; la falta de una política militar unificada y de liderazgo del poder civil sobre el estamento militar alrededor de un discurso único y una política coherente y estratégica de paz.

Seguramente esta falta de problematización del proceso de negociación y de las complejas tareas sociales y gubernamentales necesarias para obtener la paz, contribuyó también a sembrar en la opinión pública un cierto facilismo y unas expectativas falsas sobre la paz como algo fácil y rápido de lograr. Creo que hacia el futuro habría que evitar la creación de esas expectativas facilistas y ayudarle a la opinión a construir visiones complejas de los senderos de la reconciliación. De lo contrario, seguiremos como opinión pública fluctuando de manera ciclotímica entre la euforia y el desencanto con la paz, sin una capacidad de aprender colectivamente de las experiencias del pasado.

Otro problema en el cubrimiento informativo del conflicto presente sobre todo en la televisión pero también en los otros medios, tuvo que ver con la puesta en escena sensacionalista y melodramática del conflicto y la negociación en los propios formatos de opinión. Los géneros de opinión en los espacios televisivos, los cuales debieron haber ofrecido a la sociedad elementos de juicio para digerir la complejidad de la negociación en medio de la confrontación militar y haber dado fondo, contexto histórico y comparativo internacional a sus audiencias, optaron muchas veces por el sensacionalismo y el melodrama en la escogencia de sus temas y maneras de abordar el proceso de paz y de negociación y situaciones conexas con él, como el secuestro de niños por la guerrilla o la muerte -afectado por un cáncer- del niño Andrés Felipe, sin poder ver a su padre, un oficial retenido por la guerrilla. 
Esos hechos noticiosos, que por supuesto no podían no ser abordados por los medios y el periodismo, muchas veces fueron asumidos como verdaderas cruzadas mediáticas sin medir los efectos contraproducentes de esas campañas con respecto a los fines buscados (la liberación de los niños secuestrados o del padre de Andrés Felipe) y los potenciales impactos negativos sobre los climas de opinión y estados de ánimo de la población con respecto al apoyo a la negociación de paz.[3]

El cubrimiento noticioso de este tipo de situaciones mostró la dificultad del periodismo colombiano para trascender la inicial y de sentido común reacción visceral y condenatoria hacia la insurgencia, y avanzar hacia el logro de una mayor capacidad de interpelación crítica y argumentada a las acciones de la guerrilla.

Quiero en este sentido decir que los medios tienen que tener cuidado con las pasiones y estados de ánimo que propician y alimentan con sus mensajes y puestas en escena de los conflictos. Ya los propios abusos de la insurgencia (extorsión, secuestros, boleteo, asesinatos o muertes de secuestrados en cautiverio) han creado por sí solos en sus víctimas y familiares dolores, actitudes visceralmente antiguerrilleras o intenciones de retaliación y de venganza.

Tratamientos de sucesos informativos como el caso del niño Andrés Felipe, convertido en una verdadera cruzada, y otros similares que se construyeron desde los medios masivos durante los tres años largos del proceso, mostraron dificultades en el periodismo para trascender cierta lógica primaria de condena y de juzgamiento mediáticos al interlocutor guerrillero, comunicativamente bastante ineficaz para las necesidades de acercamiento entre las partes y de avance de la negociación.

Creo que en cuanto al papel del periodismo en la interpelación crítica a la insurgencia en medio de una negociación política -y esto es conveniente tenerlo en cuenta hacia el futuro cuando soplen de nuevo vientos de paz y de negociación-, requerimos trascender la acusación muchas veces moralista y facilista, desde un cierto sentido común elemental y básico de condena al guerrillero, para configurar una capacidad de interpelación ética y política al accionar insurgente que antes que condenarlo, le siembre cuestionamientos y dudas en torno a su militarismo, su falta de visión política en sus relaciones con la población, sus cercanías con la delincuencia común, sus rigideces ideológicas y anacronismos doctrinarios y le ayude a acercarse a una comprensión fresca y menos acartonada de este país: de sus nuevas generaciones, sus valores, dilemas e ideales; de la complejidad cultural y política de los contextos urbanos y metropolitanos; de las transformaciones en el plano internacional, etcétera. Interpelación inteligente, que supone diálogo y respeto por el otro, y no simplemente acorralamiento o la lógica del ajuste de cuentas a la hora de la entrevista al líder insurgente.

La zona de distensión y su caracterización como laboratorio de paz o como guarida de delincuentes fue otro de los temas álgidos alrededor del cual se dio una verdadera guerra de versiones informativas y desinformativas. Las fuentes militares y policiales, presas de su comprensible animadversión hacia su enemigo político-militar, y de sus ligerezas retóricas, metieron permanentemente notorios goles informativos que incidieron fuertemente (adicionalmente a los abusos cometidos efectivamente por la insurgencia de las FARC en la zona de despeje) en el desprestigio del Caguán y en la apreciación negativa por parte de la ciudadanía, de la marcha de las conversaciones y del mantenimiento de la zona de distensión.

El caso más grave fue el del asesinato en Simijaca el lunes 15 de mayo del 2000, de doña Elvia Cortés con un "collar-bomba" ajustado a su cuello por parte de delincuentes comunes, como posteriormente se estableció, donde sobre la base de la imputación apresurada de ese crimen a las FARC por el comandante de la Policía Nacional, el general Rosso José Serrano y por altos oficiales militares, imputación recogida acríticamente por el conjunto de los medios de comunicación y por el propio presidente Pastrana, el gobierno canceló provisionalmente una importantísima audiencia con delegados internacionales programada dentro de las conversaciones de paz, y el propio proceso de diálogo se vio afectado gravemente en sus posibilidades de continuar, por los impactos desfavorables a la negociación que esta noticia tuvo en la opinión pública.[4] 
Evaluando el caso del collar-bomba seis meses después de los hechos, el negociador oficial Fabio Valencia Cossio, planteó en estos términos el impacto negativo jugado por ese falso hecho informativo en el curso de la negociación:

"Vino el collar bomba. Hubo un error del Estado, mucha precipitud de las autoridades policiales y militares en el señalamiento de los responsables. Ese fue un rudo golpe para las FARC, que después se devolvió contra el Estado. A partir de allí las FARC endurecieron mucho su posición".[5]

En una revisión atenta de cualquier archivo noticioso televisivo de los tres años de proceso de paz con las FARC podemos encontrar numerosos y variados ejemplos de distorsiones a la información y a la verdad de los hechos, derivadas de la ideología y de los intereses estratégicos de los militares y jefes policiales en el conflicto armado interno. En el desarrollo del conflicto armado y del proceso de paz con las FARC durante el año 2000 vimos graves casos de ligereza informativa del medio noticioso televisivo, ligados a la no confirmación de la información inicial brindada por la fuente militar o policial. En el cubrimiento de la toma de las FARC a la población de Arboleda (Caldas), Noticias RCN presentó, recurriendo una vez más aventuradamente al condicional "habría", y sobre la base de la información no contrastada ni confirmada de un alto oficial de la policía, la versión, aparecida en los titulares del teleinformativo, de que "los guerrilleros habrían jugado fútbol con las cabezas de los policías". Otras versiones militares endebles y mal sustentadas que luego tuvieron que rectificarse fueron las del Comandante de la Fuerza Aérea General Héctor Fabio Velasco sobre el supuesto desembarco por parte de un avión ruso de un cargamento de armas para las FARC en la zona de distensión[6]; la supuesta muerte del Mono Jojoy anunciada por un oficial del ejército quien argumentó que tenía información fidedigna y detallada que el líder de las FARC había sido asesinado por un guerrillero a quien el Mono Jojoy le habría quitado la novia; y la aseveración de un comandante de brigada a un noticiero en términos de que una avioneta que aterrizó una madrugada en el aeropuerto Alfonso Bonilla Aragón de la ciudad de Cali venía de transportar droga desde la zona de despeje, versión que fue desmentida en la misma emisión por el propio comandante de la Fuerza Aérea, general Héctor Fabio Velasco, quien afirmó que se había establecido que la aeronave venía de dejar un cargamento de droga en Guatemala.

Tal vez refiriéndose a la falta de vocerías claras en las Fuerzas Militares y a este tipo de informaciones aventuradas por inconfirmadas que luego tienen que rectificarse o que muchas veces no se rectifican y terminan sembrando en la opinión sombras de duda sobre la confiabilidad de las versiones de la fuente militar, un experto extranjero en temas de comunicación pública afirmó en un evento sobre medios de comunicación y fuerza pública que "los militares colombianos hablan mucho y hablan muchos".[7]

Camilo Gómez, Comisionado de Paz del gobierno Pastrana desde comienzos del año 2000 hasta el cambio de gobierno de agosto de 2002 ha expresado en reciente entrevista, refiriéndose a las realidades y ficciones interesadas alrededor de la zona de despeje, que "la zona de distensión no era un paraíso pero tampoco era el infierno que muchos quisieron hacer creer".[8]

Las culturas masivas y mediáticas y las homogeneizaciones provenientes de los controles narrativos de las industrias globales de la televisión y del entretenimiento

La globalización de la industria del entretenimiento televisivo en estos comienzos de siglo XXI y la hegemonía norteamericana en el mercado de la televisión están incidiendo en la expansión en nuestros países de ciertos programas y de ciertos géneros como los talk shows y los realities, que son copiados a nivel nacional con algunas variaciones y adaptaciones a las circunstancias nacionales. Sin negar las posibilidades de adaptación innovadora que puedan darse sobre la asimilación original de esos formatos foráneos, en ellos están implícitas claras tendencias homogeneizadoras de la producción en cuanto a géneros y temáticas. Hoy día varios países latinoamericanos realizan realities o programas de concurso al estilo de "Pop Stars", "Protagonistas de novela" o "Quién quiere ser millonario". Sinembargo, no podemos rechazar estos formatos en nombre de la cultura nacional o del privilegio estrecho de lo propio en las políticas culturales y comunicativas del sector privado. Habría que ver 
sinembargo, cómo competir en el mercado global con formatos, historias y temáticas novedosas surgidas de nuestras creatividades nacionales y locales, de nuestros conflictos, idiosincracias, valores y temporalidades histórico-políticas y socio-culturales .

La producción colombiana de dramatizados ha tenido un desarrollo importante en los 80s y 90s, llegando en estas últimas décadas con "Café" y la comedia "Betty La Fea", a la conquista de importantes públicos para estas y otras producciones en decenas de países latinoamericanos, europeos y asiáticos, así como en el mercado hispano norteamericano.[9]

La búsqueda de inserción de los productos audiovisuales latinoamericanos (fundamentalmente de las telenovelas y dramatizados) parece enfrentarse en los últimos tiempos a ciertas demandas del mercado hispano norteamericano, particularmente de las comercializadoras de los dramatizados, que tal vez con miras a la conquista de amplios públicos que les representen jugosas ganancias, empiezan a requerir relatos audiovisuales desprovistos de acentos locales, regionales y nacionales, de memorias densas ancladas en la historia de nuestros pueblos, de sus pertenencias y desarraigos, y de conflictividades enraizadas en las injusticias y desequilibrios padecidos por nuestras sociedades. Pareciera ser que el formato apto para la conquista de las audiencias hispanas fuera el de "Amantes del desierto", una historia de amor bastante rosa e irreal, ubicada en un tiempo histórico inexistente por lo ambiguo de su representación (da la impresión de transcurrir a comienzos de siglo XX en alguna sociedad hacendataria pero sus personajes se visten como a comienzos del XXI), inscrita en una geografía vaga y en medio de unos conflictos muy caricaturescos y distantes de las reales conflictividades históricas y sociológicas latinoamericanas.

La información de prensa sobre el mercado del dramatizado y la telenovela latinoamericana en Norteamérica da cuenta en los últimos meses de cómo el antigalán colombiano, de pelo negro y de mediana estatura, a veces con algo de calvicie, no serviría ya para las nuevas coproducciones internacionales de novelas a ser vendidas masivamente en el mercado hispano, las cuales estarían demandando ahora con miras a su éxito galanes rubios, apuestos y corpulentos de $1.80 \mathrm{cms}$. de estatura, pero también nuevos géneros como las comedias de situaciones (sit com) inscritas en tradiciones norteamericanas de producción y de representación audiovisual de su cultura.

En cuanto a otras instancias del mercado global relacionadas con otros géneros como el documental ambiental, de ciencia y tecnología, de aventura humana o de culturas ( formatos como People and Arts, Animal Planet o Discovery Kids en Discovery Channel), si bien logran dar paso, a través de la recepción y apoyo financiero de propuestas de realización audiovisual procedentes de distintos confines del planeta, a una gran diversidad de temas, procesos e innovaciones tecnológicas, recorridos geográficos, paisajes y culturas, todo ello dentro de ciertas exigencias tecnológicas y de alta calidad en la producción audiovisual, de otro lado, en virtud de sus controles narrativos y su preocupación por el rating, terminan excluyendo temas eventualmente conflictivos o despojando de su conflictividad y de sus aristas política o socialmente espinosas y polémicas, los temas abordados. Como lo anotaba un representante de Discovery Channel en un evento realizado en Bogotá en agosto de 2001, "estamos mirando los ratings ahora" y "nos protegemos contra demandas, evitando algo que pueda causar malestar a algún grupo o persona".[10]

Fenómenos similares de homogeneización, de utilización comercial y profana de tradiciones rituales de comunidades étnicas por parte del etnoturismo y del turismo ecológico, así como de uniformización o ecualización de músicas folklóricas y étnicas, pero también de músicas más masivas como el pop, están sucediendo en la industria musical global, incluso en algunas de sus ramas alternativas como la "world music". La despolitización, el no abordaje en las canciones de temas polémicos y conflictivos que signifiquen denuncia, protesta u opción radical por alguna causa que implique algún nivel de contestación o de crítica social, sumados además a las estrategias mercadológicas de construcción del artista por parte de sus managers, constituyen hoy exigencias obligadas para el ingreso del futuro o la futura star al mercado global del espectáculo y a sus privilegios económicos y de reconocimiento simbólico y mediático.[11] 
Como se desprende de lo anterior, en el consumo cultural se están jugando también las políticas de la representación, de la memoria y la identidad nacional, así como de identidades o identificaciones mas personales y particulares.

Las implicaciones políticas de estos procesos para la teorización sobre los medios y el poder textual

Como vemos de las consideraciones presentadas en los anteriores apartes, estamos viviendo una época que demanda de los analistas culturales y de medios de comunicación una mirada crítica sobre el funcionamiento del poder mediático en los nuevos contextos de la globalización cultural y comunicativa hegemónica y en las nuevas situaciones nacionales condicionadas por esos procesos globales y por las nuevas formas de concentración de la propiedad sobre los medios de comunicación y las industrias culturales.

Esta mirada crítica no significa echar por la borda los aportes de la teoría de las mediaciones sociales y de las teorías de la recepción y de los usos sociales de la comunicación de masas, para retornar a posiciones defensivas y denuncistas de corte sesentista y setentista, del imperialismo cultural y de las perversiones de la cultura de masas y de los mass media. Pero sí significa retomar la cuestión de las implicaciones políticas del poder textual que se ejerce hoy desde y en los medios, y del control de la oferta de representaciones y sentidos detentado por los emisores de mensajes informativos y de opinión a nivel global, nacional, regional y local, y por los diseñadores de bienes simbólicos para el consumo global.

Estos nuevos tiempos imperiales, globales y nacionales, de crecimiento del poder económico y simbólico de las industrias culturales globales, de funcionamiento de los medios antes que como un foro abierto de competencia entre distintas versiones y opiniones acerca de la realidad, como instancias de control político y social de la población a través del inculcamiento de ciertas lecturas dominantes de la realidad, nos obligan a volver la mirada, y esto no deja de ser un tanto irónico, sobre la parte de verdad y el lado sensato de viejas categorías que considerábamos superadas, como "aparatos ideológicos de Estado" y "alienación".

Es claro que no se trata de volver al funcionalismo marxista en la mirada sobre las relaciones entre los medios y la sociedad, a aquellas visiones mecanicistas y absolutas donde la dominación mediática implicaba un cierre total donde la única alternativa que quedaba abierta era la de la subversión política y militar del sistema y el reemplazo del subsistema mediático por uno totalmente nuevo y revolucionario en manos del pueblo y de sus elites esclarecidas. Tampoco de retornar a la idea de la alienación como falsa conciencia, sobre la base de la suposición de que existe una conciencia verdadera, asociada a una única ideología emancipadora. Creo que de lo que se trata es de volver a pensar la dominación y el poder mediáticos, con todos los matices y problematizaciones aportados por la teoría de la recepción y de las mediaciones sociales de la comunicación en cuanto a la influencia social de los medios, pero también con todas las potencialidades en términos de alternatividad política y cultural, de pluralismo de la representación y de alteridad que esas mismas teorías entrañan. Y simultáneamente proponer políticas públicas culturales y comunicativas que democraticen y pluralicen la emisión, tanto en el plano político y cultural, y no sólo en los medios público-estatales sino también en los privados y comerciales, donde también se juega, a su manera, lo público. Políticas que hagan que la reinvindicación retórica de la diversidad cultural pregonada a menudo por los funcionarios culturales del Estado, se corresponda con un cierto equilibrio y equidad en el acceso a la emisión.

\section{A modo de conclusión:}

Estamos requiriendo, a nivel del sistema global y de los sistemas nacionales de información y de producción industrial de bienes culturales, de espacios intermedios en cuanto otros nichos o nichos alternativos para la representación escrita y audiovisual crítica del mundo actual, de nuestras sociedades nacionales, sus conflictos, esperanzas y alternativas. Las empresas públicas de medios (como Señal Colombia), los productores independientes, asociaciones 
creativas de periodistas y comunicadores sociales interesados en la construcción de ofertas informativas y simbólicas alternativas que no aspiran ni pretenden el logro de la hipermasividad en sus producciones, podrían jugar un papel importante en la constitución de esos espacios intermedios.

Este trabajo tendría que hacerse eludiendo visiones apocalípticas y condenatorias de la cultura de masas; reconociendo posibilidades, visualizando y construyendo alternativas dentro de lo masivo, pero sin ninguna ingenuidad ante las exclusiones, los controles narrativos, los monopolios de la representación, las construcciones mercadológicas y las imposiciones simbólicas de las industrias mediáticas contemporáneas.

En cuanto a la representación mediática del conflicto armado colombiano y las posibilidades de un relanzamiento en un futuro mediato de un nuevo proceso de diálogos de paz, es importante y necesario continuar la revisión crítica del comportamiento de los medios en el cubrimiento de ese proceso, pero también de las concepciones y comportamientos comunicativos de todos los actores del conflicto. La responsabilidad por la comunicación de un proceso de paz no recae sólamente en los medios y en el periodismo, sino también en los propios actores de la guerra y en sus disposiciones a ceder y a encontrar consensos y acuerdos que hagan viable la solución política negociada.

En medio de las tendencias imperiales anotadas al comienzo de este artículo, de las homogeneizaciones derivadas de las políticas e ideologías antiterroristas estimuladas por el nuevo contexto internacional creado luego de los atentados terroristas contra las torres Gemelas y el Pentágono el 11 de septiembre del 2001, es muy importante hacia el futuro de los acuerdos de paz con las guerrillas de las FARC y el ELN, mantener en la política colombiana una perspectiva estratégica de negociación política que reconozca el status político de la guerrilla (a pesar de todos sus cruces con acciones de delincuencia común), que evite fenómenos de bandolerización ya vividos en anteriores reincorporaciones de insurgentes a la vida civil de las cuales tendríamos que aprender, y que posibilite y estimule la ampliación del espectro político y la conformación de fuerzas políticas alternativas en el país, para que ese potencial guerrillero de destrucción y de contestación por la vía de las armas pueda reconvertirse en un potencial de creación y construcción, de apertura democrática de la vida política y de trabajo por la justicia social desde la vida civil.

No sobra recordar, concluyendo estas reflexiones, que en medio de las actuales circunstancias colombianas mantiene una inmensa validez la tesis del maestro Jesús Martín-Barbero sobre la profunda contradicción existente en Colombia entre la opulencia tecnológica de nuestros medios masivos de comunicación y la brutal incomunicación en que vivimos los colombianos:

"En Colombia los años 80 han sido los años del despliegue de las industrias de comunicación. Tenemos uno de los sistemas de radio más modernos de América Latina y un buen desarrollo de la televisión, tanto en el aspecto tecnológico y empresarial como en el de la competencia comunicativa y estética. Estamos asistiendo al despliegue de toda la parafernalia tecnológica de los enlaces vía satélite, las antenas parabólicas, las redes de cable y la telefonía celular. Pero al mismo tiempo Colombia vive uno de los quiebres más profundos en la comunicación de sus colectividades. Es una paradoja bien flagrante: Pocos países viven un desarrollo tan pujante de los medios y las tecnologías y una crisis tan honda de la convivencia, de la comunicación entre las colectividades que lo conforman como pueblo, como nación".[12]

\footnotetext{
* Historiador y analista cultural y de medios de comunicación. Director Instituto de Estudios en Comunicación y Cultura - IECO, Universidad Nacional de Colombia
}

[1] En el tratamiento del tema de los medios de comunicación y el cubrimiento del conflicto armado y el proceso de paz por el periodismo colombiano nos basamos en el informe final de la investigación "Rutinas profesionales y discursos 
hegemónicos en la información periodística sobre conflicto armado y proceso de paz con las FARC en Colombia durante 1999", financiada por Colciencias y realizada desde el Instituto de Estudios Políticos y Relaciones Internacionales IEPRI de la Universidad Nacional de Colombia, bajo la dirección del autor de este artículo, y con la participación en calidad de coinvestigadores de los profesores Nelson Castellanos y Leandro Peñaranda.

[2] Véase sobre el papel de algunas de esas programadoras y en particular de RTI, el aparte "Del teleteatro a la telenovela: géneros televisivos y modernidad cultural", en Martín-Barbero, Jesús y Rey, Germán, Los ejercicios del ver. Hegemonía ausdiovisual y ficción televisiva, Gedisa, Barcelona, 1999.

[3] Sobre el cubrimiento del caso del niño Andrés Felipe véase la opinión del analista mexicano Carlos Monsiváis invitado como ponente central a la conferencia internacional "Los medios informativos en peligro", organizada por la Asociación Mundial de Periódicos (WAN), la Sociedad Interamericana de Prensa (SIP) y la Asociación de Diarios Colombianos (Andiarios) el viernes 22 de marzo de 2002 en Bogotá, Entrevista a Carlos Monsiváis, El Tiempo, sábado 23 de marzo de 2002

[4] Sobre estos impactos negativos, las reacciones de la opinión a la noticia del "collar-bomba", así como las movilizaciones estudiantiles de condena a las FARC y la atmósfera de consternación ante la barbarie guerrillera que presidió el entierro de doña Elvia en Chiquinquirá, reacciones todas suscitadas por este falso suceso informativo, pueden consultarse los periódicos El Tiempo y El Espectador de los días 17 y 18 de mayo de 2000.

[5] "Paciencia y fe", Paz. Especial 2.000, Artículo de Fabio Valencia Cossio, El Espectador, 31 de diciembre de 2.000, p.B2

[6] Véase el noticiero "En Vivo 9:30", emisión del jueves 14 de octubre de 1999 y "Noticias RCN", emisiones de las 7:00 y las 9:30 de la noche del mismo día.

[7] Foro sobre Medios de Comunicación y Fuerza Pública, Paipa, noviembre de 2001

[8] "FARC, autistas y vendedoras de falsas ilusiones", Entrevista con el Comisionado de Paz Camilo Gómez, Lecturas Dominicales de "El Tiempo", domingo 28 de julio de 2002, p.3

[9] Véase especialmente el capítulo 3 "Transformaciones del género: de la telenovela en Colombia a la telenovela colombiana", en: Martín-Barbero, Jesús y Sonia Muñoz (coordinadores), Televisión y melodrama, Tercer Mundo Editores, Bogotá, 1992

[10] Intervención de Lorenzo Dunoyer, de Discovery Channel en el Encuentro de Televisión Educativa y Cultural realizado por las universidades Nacional y Javeriana de Bogotá en la Universidad Nacional de Colombia, agosto de 2001 (apuntes personales del autor de este trabajo).

[11] Sobre estos temas, puede consultarse el escrito del etnomusicólogo brasileño José Jorge de Carvalho "Perspectivas de las culturas afroamericanas en el desarrollo de Iberoamérica" (mimeo), 2002

[12] Martín-Barbero, Jesús, "Comunicación y modernidad en América Latina", en Martín-Barbero, Jesús, Pre-Textos. Conversaciones sobre la comunicación y sus contextos, Centro Editorial Universidad del Valle, Cali, 1995, p.167 